\title{
Hierarchical linear models in psychiatry: A bibliometric study
}

\author{
Víctor H. Cervantes, ${ }^{\mathrm{a}}$ AnA Cristina SANTANA, ${ }^{\mathrm{a}}$ GeOrgina GuILERA, ${ }^{\mathrm{b}}$ \\ JUANA GÓMEZ-BENITO ${ }^{b}$ \\ a Universidad Nacional de Colombia, Bogotá, Distrito Capital, Colombia \\ ${ }^{\mathrm{b}}$ Universidad de Barcelona, Barcelona, Spain
}

\begin{abstract}
Development of research methods requires a systematic review of their status. This study focuses on the use of Hierarchical Linear Modeling methods in psychiatric research. Evaluation includes 207 documents published until 2007, included and indexed in the ISI Web of Knowledge databases; analyses focuses on the 194 articles in the sample. Bibliometric methods are used to describe the publications patterns. Results indicate a growing interest in applying the models and an establishment of methods after 2000. Both Lotka's and Bradford's distributions are adjusted to the data.
\end{abstract}

\section{Introduction}

Hierarchical linear modeling (HLM) has been developed to properly account for nested structures in the statistical treatment of data [BRYK \& RAUDENBUSH, 1992]. Such structures are frequent in human health research, therefore HLM becomes pertinent for psychiatric and psychological research; for instance, these models aid exploring how social environment characteristics relate to schizophrenia incidence [VAN OS \& AL., 2000; AllardyCE \& BOYdell, 2006; DRUKKER \& AL., 2006]; allow the analysis of dyad processes of caregiving [LYONS \& SAYER, 2005]; and may consider individual change as it appears in longitudinal studies [HEDEKER \& MERMELSTEIN, 1996, 2000].

The HLM strategy addresses the nested structure by introducing multiple levels of models according to the hierarchy implied by such a structure [BRYK \& RAUDENBUSH, 1992]. As an illustration, let us assume that the severity of an illness in hospitalized patients increases linearly with time but at different rates associated with patients' characteristics, such as their quality of life $(Q o L)$; furthermore, let us assume that the effect of quality of life is not the same in all institutions. Thus, we might express the illness severity in time $\mathrm{t}$ for patient $\mathrm{i}$ hospitalized at institution $\mathrm{j}$ by the model: $y_{i j t}=\beta_{0}+\beta_{1 i j} t+\varepsilon_{i j t}$ at observations level, while expressing the differing rates by the model: $\beta_{1 i j}=\gamma_{0}+\gamma_{1 i} Q o L_{i j}+u_{1 i j}$ at patient level, and expressing the varying effect of QoL by the model: $\gamma_{1 i}=u_{2 i}$ at institution level. This formulation may account for the

Received April 25, 2008; Published online April 16, 2009

Address for correspondence:

VÍCTOR H. CERVANTES

E-mail: vhcervantesb@unal.edu.co 
association of observations from the same patient and the clustering of patients within an institution by including the second and third level models which in turn include a number of higher level random-effects and cross-level interactions, as can be seen if we write the three models in a single expression, known as the combined model: $y_{i j t}=\beta_{0}+\gamma_{0} t+u_{1 i j} t+u_{2 i j} Q o L_{i j} t+\varepsilon_{i j t}$, where a random-effect of the individual patient affects how the severity varies in time $\left(u_{1 i j} t\right)$ and a random-effect of the institution affects the interaction between patient $Q o L$ and observation time $\left(u_{2 j} Q o L_{i j} t\right)$, while simultaneously considering a fixed mean change rate $\left(\gamma_{0} t\right)$ and a fixed severity baseline $\left(\beta_{0}\right)$.

This modeling strategy is relatively recent, having been developed during the 1980's; and although psychiatric research has seen a tendency towards a broader use of innovative statistical methods [MIETTUNEN \& AL., 2002], it is unclear how much HLM has permeated psychiatric research - v.g. in ALLARDYCE \& BOYDELL's [2006] review, only 4 of the 13 articles they analyzed used HLM. For these reasons, a more systematic review of the current status of the use of these statistical methods in Psychiatry ought to be pursued.

Bibliometrics systematically study written publications, and so can be used to assess the methodological aspects of published researches [MIETTUNEN \& AL., 2002]. Their methods have been successfully applied to psychiatric research to evaluate the activity of bipolar disorder research [CLEMENT \& AL., 2003], the diagnostic criteria used [ARAGONA, 2006], the use of statistical methods in psychiatric research and their relation to article citations rates [MIETTUNEN \& AL., 2002; MIETTUNEN \& NiEMINEN, 2003], among other subjects. In this review, we aim to evaluate the reception of HLM in psychiatric research by means of the bibliometric analysis methodology.

\section{Method}

\section{Data collection}

The documents included in the present study were identified via a database search in the Web of Knowledge (WoK) site of the Institute for Scientific Information (ISI) from Thompson Scientific. The search took place on January 2008 and included the Science Citation Index Expanded (SCIE), the Social Sciences Citation Index (SSCI) and the Arts \& Humanities Citation Index (A\&HCI) databases.

Aiming to cover all the available documents on the subject, the search strategy was based on documents published in journals in 2007 or before, the key words "multilevel*", "hierarchical linear model*" and "hlm", and on the subject "Psychiatry". Furthermore, since both "multilevel*" and "hlm" search terms might also include papers on subjects unrelated to HLM, the 229 documents obtained from both terms were screened, either by analyzing their abstracts or searching for the full text document, in order to ensure that only HLM related documents were included in the 
study. The search resulted in a total of 207 documents included in the study and 82 documents rejected for not being HLM related.

\section{Data analysis}

The documents were tabulated using ActivePerl 5.10.0 [ACTIVE STATE SofTware INC., 2008] and Excel 2007. The coded variables were year of publication, authors, number of authors, institutions, number of institutions, countries, number of countries, type of document (article, review, meeting abstract and editorial material), total number of citations received, citations received each year (starting in the year of the first published document), subject and keywords (both those included by the document itself and those included by the database).

The indices used in this study were the Citations Per Publication Index (CPP), the Publication Efficiency Index (PEI), the Co-Authorship Index (CAI), the Hirsch index (h-index) and the g-index. The PEI gives a relative measure for the CPP index and is calculated as the CPP divided by the rate of all citations received and all documents produced in the analyzed sector [GUAN \& MA, 2007]; this corresponds to various relative indices such as CPP/FCSm and CPP/JCSm ${ }^{1}$ [VAN RAAN, 2003, 2006], where the sector analyzed is the world journal population working on the same field and the world journal population the unit has published in, respectively. For this study the sector of comparison is the HLM related documents published in "Psychiatry" and indexed by ISI-WoK.

The CAI is presented by GUAN \& MA [2007] as a derivation of relative activity. The h-index was proposed by HIRSCH [2005] as a simple indicator of the cumulative impact of an individual's research work. EGGHE [2006] proposed the g-index analogously to Hirsch's h-index. The g-index is presented as an improvement of the h-index to measure the global citation performance of a set of articles. In this study, following BRAUN \& AL.'s [2006] and SAAD's [2006] results and the direction implied in Egghe's g-index, we apply both the h-index and the g-index to journal production rather than author production.

Both Lotka's [LOTKA, 1926], used to describe author productivity within a given field or set of journals, and Bradford's law [BRADFORD, 1934/1985], used for describing the scattering of articles, were applied. According to POTTER [1981] the sole requisite for applying Lotka's law is that the data is retrieved from a time span covering at least ten years. Nevertheless, the law does not hold for all sets of productivity structures in all fields [GLÄNZEL, 2003], but when it does, it is a very useful tool for describing and predicting how many authors are to be expected to have published a given number of articles, thus describing the diffusion of the particular field among

\footnotetext{
${ }^{1}$ The abbreviation FCSm represents the mean Field Citation Score and JCSm the mean Journal Citation Score.
} 
researchers. The law is defined in several places (v.g. [LOTKA, 1926; GLÄNZEL, 2003]), and different methods for parameter estimation, such as maximum likelihood [NICHOLLS, 1986, 1989], and for assessing the law's fit [PAO, 1985; NiCHOLLS, 1986, 1989; LOUGHNER, 1992], are available.

The Bradford multiplier was obtained by $\mathrm{k}=\left(1.781 \times Y_{0}\right)^{1 / \mathrm{P}}$, where $Y_{0}$ is the number of articles published in the subject by the most productive journal and $P$ is the number of zones including the nucleus [EGGHE, 1986, 1990]. LEIMKUHLER's [1967] formulation of this law with constants $A$ and $B$ obtained as $A=y_{0} / \ln k$ and $B=(k-1) / N_{0}$, where $k$ is as defined above, $N_{0}$ is the number of journals in the core and $y_{0}$ is the constant number of articles in each group [GLÄNZEL, 2003], was also fitted. A Bradford-Zipf plot may be used to represent both the observed cumulative frequency of articles by journal rank and the Leimkuhler's formulation predicted frequencies.

All analyses were performed with R 2.6.2 [R DEVELOPMENT CORE TEAM, 2008].

\section{Results}

\section{Type of document and year of publication}

One hundred and ninety-four of the 207 documents in the search are classified as articles by the ISI-WoK databases. Remaining analyses will be based only on these documents, which represent $93.72 \%$ of total recovered documents. The remaining 13 documents are classified either as reviews, meeting abstracts or editorial materials. Figure 1 shows both the frequencies of psychiatric articles published regarding HLM models each year and their cumulative frequencies. Articles on HLM started appearing in 1989, and a seemingly exponential growing trend can be observed, especially at the beginning of the current decade.

\section{Authors}

The total number of articles analyzed includes 679 authors. However some of them have published on more than one occasion and an article may be the product of more than one author, thus the total number of contributions rises to 843 . The number of authors that contribute to each article ranged from one to fifteen. Seven articles $(3.61 \%)$ were written by a single author, $17.53 \%$ have 2 authors, $20.62 \%$ have 3 authors, $21.13 \%$ have 4 authors, $21.13 \%$ have 5 or 6 authors and $15.98 \%$ include more than six authors.

The number of authors over time stabilized around 4.5 authors per article during the current decade, during the 90's the small number of publications makes it impossible to identify a pattern. It can also be noted that there is a small group of authors that have contributed highly with publications related to HLM. Table 1 presents the distribution of author productivity. The output of the top contributing authors accounts for $10.32 \%$ of the total contributions. 
a) Number of articles per year

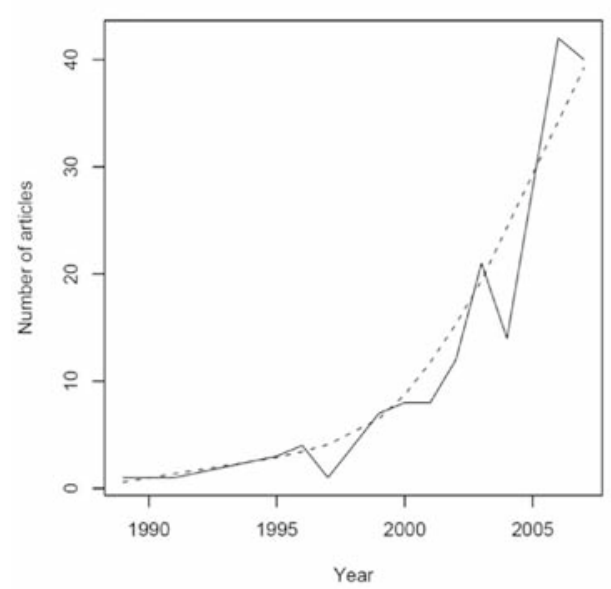

b) Cumulative articles per year

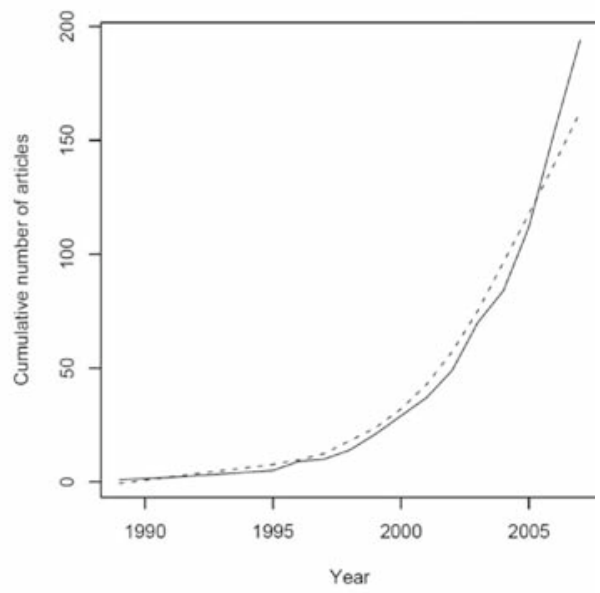

Figure 1. Temporal evolution of publications on HLM: a) number of articles per year;

b) cumulative number of articles by year

Table 1. Author production

\begin{tabular}{rccccc}
\hline $\begin{array}{c}\text { Number of } \\
\text { Authors }\end{array}$ & Contributions & $\begin{array}{c}\text { Contribution } \\
\text { percentage }\end{array}$ & $\begin{array}{c}\text { Author } \\
\text { percentage }\end{array}$ & $\begin{array}{c}\text { Cumulative } \\
\text { author \% }\end{array}$ & $\begin{array}{c}\text { Predicted } \\
\text { cumulative } \\
\text { author \% }\end{array}$ \\
\hline 586 & 1 & 69.51 & 86.303 & 86.303 & 86.985 \\
73 & 2 & 17.32 & 10.751 & 97.054 & 95.715 \\
8 & 3 & 2.85 & 1.178 & 98.233 & 97.990 \\
5 & 4 & 2.37 & 0.736 & 98.969 & 98.866 \\
2 & 5 & 1.19 & 0.295 & 99.264 & 99.284 \\
2 & 8 & 1.9 & 0.295 & 99.558 & 99.737 \\
1 & 9 & 1.07 & 0.147 & 99.705 & 99.796 \\
1 & 10 & 1.19 & 0.147 & 99.853 & 99.838 \\
1 & 22 & 2.61 & 0.147 & 100.00 & 99.972 \\
\hline
\end{tabular}

For the analyzed articles the estimated power n of Lotka's law was 3.317, giving a constant value $\mathrm{C}=0.869$. The percentages predicted by Lotka's law are depicted in the last column of Table 1. The difference between the observed and predicted distributions was assessed using the K-S test, which yielded a $\mathrm{D}_{\max }=0.013$, c.v. $=0.062$. These results show that the power distribution described by Lotka's law is appropriate to model the productivity of authors using the HLM methodology in Psychiatry.

\section{Institutions}

A total of 269 institutions were found, and given that several institutions may participate in a single article, the total institutional contributions were 454. Institution productivity is presented in Table 2 . Each section depicts the top five institutions given 
the bibliometric indicators employed. Thus, the first shows the five institutions whose researchers have produced most papers related to HLM; the second presents the five institutions whose articles have been cited the most; and the last, those whose efforts around HLM have had the biggest impact. Note that the most productive institutions are universities. It is also interesting to point out that only two of the top five most productive institutions received a higher than average number of citations, while the universities that received the highest number of citations per article on HLM have produced only a small number of these.

Table 2. Bibliometric indicators for the five a) most productive, b) most cited and c) highest relative impact institutions

\begin{tabular}{|c|c|c|c|c|c|c|}
\hline Indicator & Institution & Publications & Citations & Publications \% & CPP & PEI \\
\hline \multirow{5}{*}{$\begin{array}{c}\text { Top } \\
\text { number of } \\
\text { publications }\end{array}$} & University of Maastricht & 26 & 360 & 5.727 & 13.846 & 1.614 \\
\hline & $\begin{array}{l}\text { Institute of Psychiatry, } \\
\text { Div Psychol Med, London }\end{array}$ & 18 & 267 & 3.965 & 14.833 & 1.729 \\
\hline & Harvard University & 10 & 61 & 2.203 & 6.1 & 0.711 \\
\hline & Yale University & 9 & 76 & 1.982 & 8.444 & 0.984 \\
\hline & Michigan University & 8 & 42 & 1.762 & 5.25 & 0.612 \\
\hline \multirow{5}{*}{$\begin{array}{c}\text { Top } \\
\text { number of } \\
\text { citations }\end{array}$} & University of Maastricht & 26 & 360 & 5.727 & 13.846 & 1.614 \\
\hline & $\begin{array}{l}\text { Institute of Psychiatry, } \\
\text { Div Psychol Med, London }\end{array}$ & 18 & 267 & 3.965 & 14.833 & 1.729 \\
\hline & Groningen University & 2 & 116 & 0.441 & 58 & 6.76 \\
\hline & University of Liège & 1 & 110 & 0.22 & 110 & 12.822 \\
\hline & Texas Christian University & 1 & 97 & 0.22 & 97 & 11.306 \\
\hline \multirow{5}{*}{ Top PEI } & University of Liège & 1 & 110 & 0.22 & 110 & 12.822 \\
\hline & Texas Christian University & 1 & 97 & 0.22 & 97 & 11.306 \\
\hline & Suny, Stony Brook University & 1 & 59 & 0.22 & 59 & 6.877 \\
\hline & University of Groningen & 2 & 116 & 0.441 & 58 & 6.76 \\
\hline & $\begin{array}{l}\text { King's College Hospital, } \\
\text { University of London }\end{array}$ & 1 & 58 & 0.22 & 58 & 6.76 \\
\hline
\end{tabular}

\section{Countries}

There are 23 countries participating in psychiatric applications of HLM. Taking into account that authors from different countries may contribute to the same article, the total contributions of countries amounted 251. Countries were ranked from highest to lowest productivity. The seven top contributing countries were the USA with 107 contributions (42.63\%), the Netherlands (15.94\%), England (15.54\%), Canada (4.78\%), Germany (3.59\%), and Australia and Switzerland (2.39\% each). It should be noted that the United States of America accounts for about two fifths of the contributions, and that 
the top three contributing countries account for $74.1 \%$ of contributions. Also, work in HLM methods among these countries was pioneered by researchers from the United States in 1989, and contributions from this country have increased over time. Contributions from the Netherlands and England have been steady during the current decade.

The nature of collaboration of an international or intranational kind was explored in relation to the number of authors collaborating in each article (shown in Figure 2a), as well as related to the countries from which the authors participated (shown in Figure $2 b$ ). Since all papers produced by a single author imply no official collaboration, no papers by a single author were included in Figure 2a.

a) Type of collaboration per number of authors

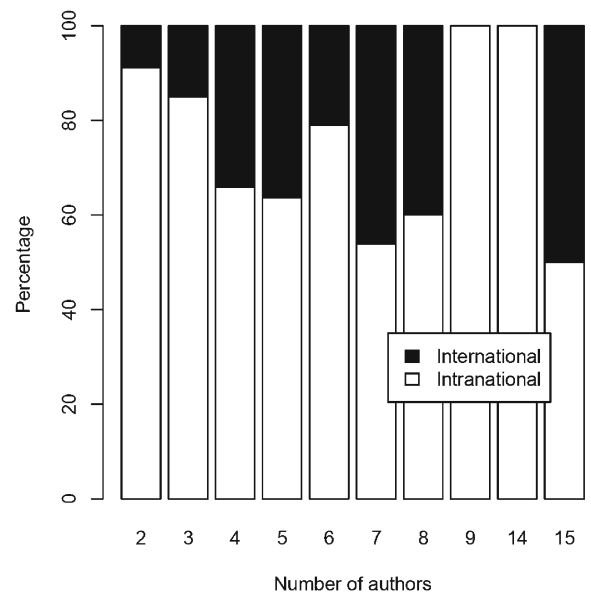

b) Type of collaboration per countries

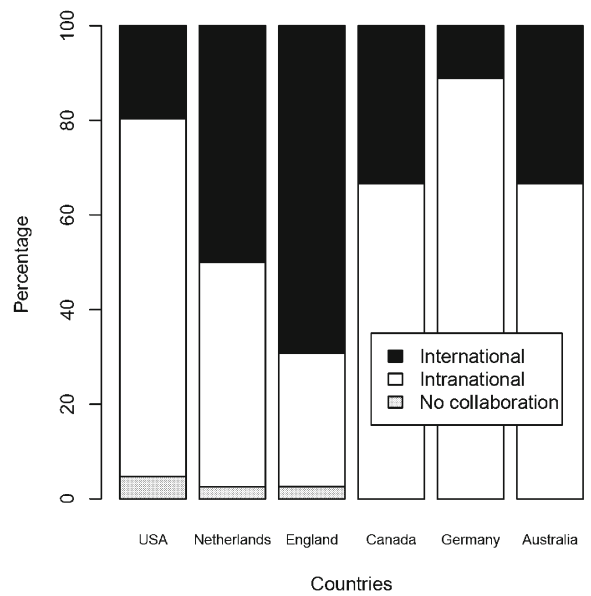

Figure 2. Collaboration patterns a) by number of authors and b) by most productive countries

Note that the majority of collaborations in articles are of an intranational nature, with the highest rates of international collaboration occurring in the articles produced by 7 or 8 authors, the highest rate $(50 \%)$ shown for 15 authors represents one article of exclusively intranational collaboration and one article of an international kind. On the kind of collaboration found among the top producing countries, the highest rates of international collaboration appear in Switzerland (83.3\%, not shown in figure), the Netherlands and England, while the USA and Germany present the highest rates of only intranational collaboration and of single-authored articles. It is worth pointing out that only the USA, the Netherlands and England appear with articles published by a single author, all articles from other countries report some form of collaboration. 
In order to better assess the collaboration patterns in each country, the CoAuthorship Index (CAI) presented by GUAN \& MA [2007] was obtained for the top seven collaborating countries and is presented on Table 3. The papers have been classified into single-authored, two-authored, multiple-authored when three or four authors participated, and mega-authored when five or more authors were involved. It can be seen that the trend in the USA is for articles produced by one or two authors, that in Switzerland it is more common to produce articles by two authors, while in the other countries the presence of multiple-authored and even mega-authored articles is relatively common.

Table 3. Co-Authorship Index for top seven contributing countries

\begin{tabular}{lcccc}
\hline Country & Single & Two & Multiple & Mega \\
\hline USA & 1.676 & 1.395 & 0.934 & 0.880 \\
Netherlands & 0.896 & 0.509 & 1.279 & 0.905 \\
England & 0.919 & 0.522 & 1.062 & 1.114 \\
Canada & 0 & 1.696 & 1.015 & 0.804 \\
Germany & 0 & 0 & 1.354 & 1.073 \\
Australia & 0 & 1.131 & 0.812 & 1.207 \\
Switzerland & 0 & 2.261 & 0.812 & 0.804 \\
\hline
\end{tabular}

\section{Journals}

The articles analyzed were published in 56 different journals. Journal productivity is presented in Table 4. Each section depicts the top six journals given the bibliometric indicators employed. Thus, the first section shows the journals that have published most papers related to HLM; the second presents the journals whose articles have been cited the most; the third, those whose efforts around HLM have had the biggest impact as assessed by the PEI indicator, whereas the fourth does so according to the $\mathrm{h}$ and $\mathrm{g}$ indexes.

It should be noted how each index provides a different insight into the productivity of different journals regarding HLM methods. Overall, it can be observed that the greatest interest has occurred in applications of these models in substance abuse contexts. It is also interesting that while the CPP index and PEI weighting of both publications and citations seems to help pointing toward single, highly influential articles published in the journal, the $\mathrm{h}$ and, specially, the $\mathrm{g}$ indices do so towards a sustained and influential work on the area within the journal.

The first appearance of an article using HLM on the most productive journals occurred in 1996, seven years after the first article published in Psychiatry using HLM; while the most productive journal did not begin publishing in this area until 2001, more than a decade later. All journals in the top productivity ranking have shown a steady production since they started addressing this subject. Both the publication and citation of articles in this area became frequent by the end of the 90's and the beginning of this century. This shows a rather recent establishment of HLM methods in the psychiatric field. 
Table 4. Bibliometric indicators for the a) most productive, b) most cited, c) highest relative impact and d) highest $\mathrm{h}$ and $\mathrm{g}$ indices for journals on HLM

\begin{tabular}{|c|c|c|c|c|c|c|c|c|}
\hline Indicator & Journal & Publications & Citations & Publications, \% & CPP & PEI & h-index & g-index \\
\hline \multirow{6}{*}{$\begin{array}{c}\text { Top } \\
\text { number of } \\
\text { publications }\end{array}$} & Drug and Alcohol Dependence & 15 & 48 & 7.732 & 3.2 & 0.345 & 4 & 6 \\
\hline & Addiction & 12 & 199 & 6.186 & 16.583 & 1.789 & 5 & 12 \\
\hline & Psychosomatic Medicine & 11 & 229 & 5.67 & 20.818 & 2.246 & 6 & 11 \\
\hline & $\begin{array}{l}\text { Social Psychiatry and Psychiatric } \\
\text { Epidemiology }\end{array}$ & 11 & 72 & 5.67 & 6.545 & 0.706 & 4 & 8 \\
\hline & Substance Use \& Misuse & 11 & 81 & 5.67 & 7.364 & 0.795 & 5 & 9 \\
\hline & Psychological Medicine & 10 & 148 & 5.155 & 14.8 & 1.597 & 8 & 10 \\
\hline \multirow{6}{*}{$\begin{array}{c}\text { Top } \\
\text { number of } \\
\text { citations }\end{array}$} & Psychosomatic Medicine & 11 & 229 & 5.67 & 20.818 & 2.246 & 6 & 11 \\
\hline & Addiction & 12 & 199 & 6.186 & 16.583 & 1.789 & 5 & 12 \\
\hline & Psychological Medicine & 10 & 148 & 5.155 & 14.8 & 1.597 & 8 & 10 \\
\hline & British Journal of Psychiatry & 6 & 95 & 3.093 & 15.833 & 1.708 & 3 & 6 \\
\hline & $\begin{array}{l}\text { Journal of Child Psychology and } \\
\text { Psychiatry and Allied Disciplines }\end{array}$ & 9 & 82 & 4.639 & 9.111 & 0.983 & 5 & 9 \\
\hline & Journal of Clinical Psychiatry & 3 & 81 & 1.546 & 27 & 2.913 & 3 & 3 \\
\hline \multirow{6}{*}{ Top PEI } & Journal of Clinical Psychiatry & 3 & 81 & 1.546 & 27 & 2.913 & 3 & 3 \\
\hline & American Journal of Psychiatry & 1 & 21 & 0.515 & 21 & 2.266 & 1 & 1 \\
\hline & Psychosomatic Medicine & 11 & 229 & 5.67 & 20.818 & 2.246 & 6 & 11 \\
\hline & $\begin{array}{l}\text { Journal of Neurology Neurosurgery } \\
\text { and Psychiatry }\end{array}$ & 1 & 20 & 0.515 & 20 & 2.158 & 1 & 1 \\
\hline & Archives of General Psychiatry & 4 & 76 & 2.062 & 19 & 2.05 & 3 & 4 \\
\hline & $\begin{array}{l}\text { Journal of Intellectual } \\
\text { Disability Research }\end{array}$ & 1 & 18 & 0.515 & 18 & 1.942 & 1 & 1 \\
\hline \multirow{6}{*}{$\begin{array}{c}\text { Top } \\
\mathrm{h} \text { and } \mathrm{g} \\
\text { indices }\end{array}$} & Addiction & 12 & 199 & 6.186 & 16.583 & 1.789 & 5 & 12 \\
\hline & Psychosomatic Medicine & 11 & 229 & 5.67 & 20.818 & 2.246 & 6 & 11 \\
\hline & Psychological Medicine & 10 & 148 & 5.155 & 14.8 & 1.597 & 8 & 10 \\
\hline & Substance Use \& Misuse & 11 & 81 & 5.67 & 7.364 & 0.795 & 5 & 9 \\
\hline & $\begin{array}{l}\text { Journal of Child Psychology and } \\
\text { Psychiatry and Allied Disciplines }\end{array}$ & 9 & 82 & 4.639 & 9.111 & 0.983 & 5 & 9 \\
\hline & $\begin{array}{l}\text { Social Psychiatry and Psychiatric } \\
\text { Epidemiology }\end{array}$ & 11 & 72 & 5.67 & 6.545 & 0.706 & 4 & 8 \\
\hline
\end{tabular}

The distribution of articles published by journals as described using Bradford's law is presented in Table 5 where 8 zones were identified. The table shows the number of journals in each zone $\left(N_{n}\right)$, the expected number of journals in each zone given by the $\mathrm{k}$ multiplier, the number of articles per zone, the cumulative number of articles and the estimated values of $\mathrm{k}, \overline{k_{n}}=\sqrt[n]{N_{n} / N_{0}}$. According to Leimkuhler's formulation of Bradford's distribution, Figure 3 presents the Bradford-Zipf plot of observed and predicted cumulative articles published by journal rank. The estimated parameters for Leimkuhler's formulation were $\mathrm{A}=59.05$ and $\mathrm{B}=0.44$, while the $\mathrm{k}$ multiplier was 
1.44. Both Bradford's law and Leimkuhler's formulation seem to fit the observed distribution very well. It should be noted, however, that the data cannot perfectly fit a Bradford's law given that the most productive journal has less than 16 publications [EGGHE, 1986]; this can be observed in zones 1 to 3, which all have the same number of journals (2) instead of the strictly increasing number required in the law.

Table 5. Bradford's distribution

\begin{tabular}{lccccc}
\hline Zone & $N_{0}$ & $\overline{N_{n}}$ & $\begin{array}{c}\text { Number of } \\
\text { articles }\end{array}$ & $\begin{array}{c}\text { Cumulative } \\
\text { articles }\end{array}$ & $\overline{k_{n}}$ \\
\hline Nucleus & 1 & 1 & 15 & 15 & - \\
Zone 1 & 2 & 1.4406 & 23 & 38 & 2 \\
Zone 2 & 2 & 2.075 & 22 & 60 & 1.414 \\
Zone 3 & 2 & 2.989 & 19 & 79 & 1.259 \\
Zone 4 & 4 & 4.306 & 25 & 104 & 1.414 \\
Zone 5 & 5 & 6.204 & 22 & 126 & 1.378 \\
Zone 6 & 7 & 8.937 & 23 & 149 & 1.383 \\
Zone 7 & 11 & 12.874 & 22 & 171 & 1.408 \\
Zone 8 & 22 & 18.546 & 23 & 194 & 1.472 \\
\hline
\end{tabular}

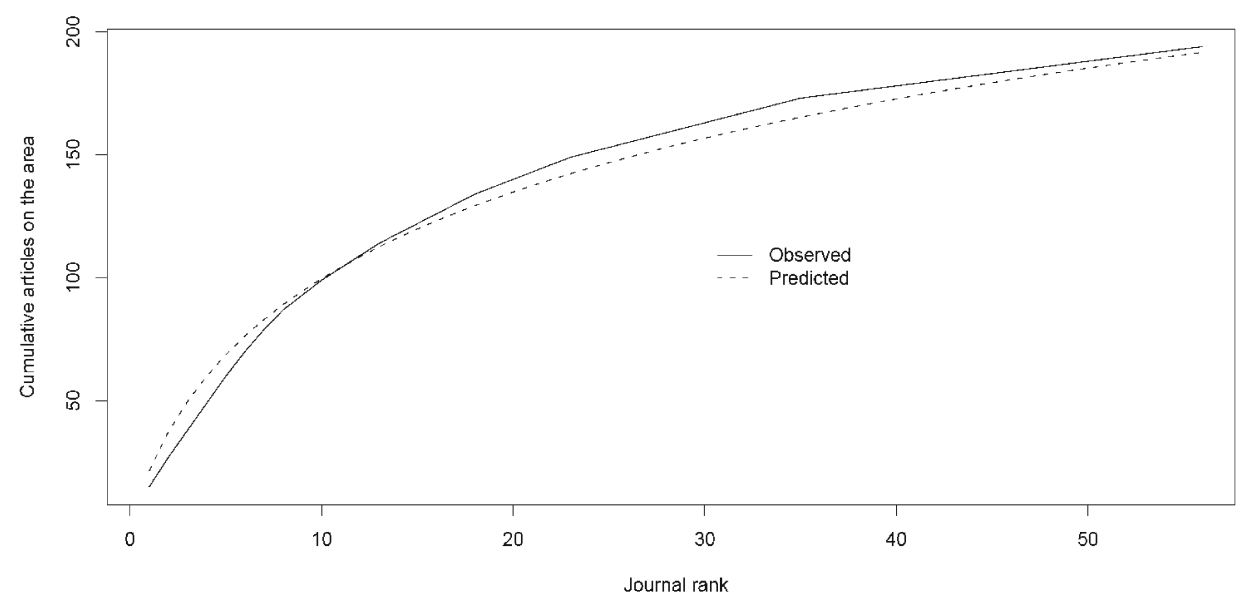

Figure 3. Bradford-Zipf plot

\section{Discussion}

The results show evidence of an increasing interest in using HLM in Psychiatry, yet contrary to ALLARDYCE \& BOYDELL's [2006] perception, establishment of multilevel 
modeling does not seem to have occurred until the beginning of the current decade. A good reception of the HLM strategy is evident both in the USA and in Europe; the latter further revealing the existence of research groups specially interested in their application, mainly in the Netherlands at University of Maastricht and in England at the Institute of Psychiatry's Division of Psychological Medicine and Psychiatry, as evidenced by the application of Lotka's law and the institutional distribution of articles. Also, a broader knowledge and production using HLM is evident from USA, however the existence of a group focused on their application to psychiatric issues is not evident. It should be noted that Switzerland, the Netherlands and England are the countries with highest international collaboration patterns in these documents.

The scattering of journals, despite following Leimkuhler's formulation, does not provide evidence of a small set of key journals focused on documents using HLM; however, there seems to be a higher application of the strategy to questions related to substance use and abuse. The subjects and topics addressed by publications using HLM will be evaluated in a future study by the authors.

It is a limitation of the present study that the observed results might be biased by the search scope. Given the specific key words used for the search and the reliance on only journals reported in the databases used (ISI-WoK), it is possible that related articles have been omitted if the keywords were not included in their database tags, or if the relevant article was not cited in the database.

The first and second authors have been supported by grants "Programa de Movilidad Internacional de Investigadores e Innovadores a eventos y estancias de corta duración" of Instituto Colombiano para el desarrollo de la Ciencia y la Tecnología - Colciencias and "Programa de Movilidad Académica entre Instituciones asociadas a la AUIP” of "Asociación Universitaria Iberoamericana de Postgrado".

\section{References}

Active State Software Inc. (2008), ActivePerl 5.10.0 Standard Distribution [Computer software]. Vancouver, Canada. Retrieved from http://www.activestate.com/Products/activeperl/

Allardyce, J., Boydell, J. (2006), Review: The wider social environment and schizophrenia. Schizophrenia Bulletin, 32 (4) : 592-598.

ARAGONA, A. (2006), A bibliometric analysis of the current status of psychiatric classification: the DSM model compared to the spectrum and the dimensional diagnosis. Giornale Italiano di Psicopatologia, $12: 342-351$.

Braun, T., Glänzel, W., Schubert, A. (2006), A Hirsch-type index for journal. Scientometrics, 69 (1) : 169-173.

BRADFORD, S. C. (1985), Sources of information on specific subjects. Journal of Information Science, $10: 176$ - 180. Original work published in 1934 in Engineering, $137: 85-88$.

BRYK, A. S., RAUdEnBUSH, S. W., Hierarchical Linear Models. SAGE Publications, London, 1992.

Clement, S., Singh, S., Burns, T. (2003), Status of bipolar disorder research: bibliometric study. British Journal of Psychiatry, $182: 148-152$. 
CERVANTES \& AL.: Hierarchical linear models in psychiatry

DrukKer, M., Krabbendam, L., Driessen, G., VAn Os, J. (2006), Social disadvantage and schizophrenia: a combined neighborhood and individual-level analysis. Social Psychiatry and Psychiatric Epidemiology, 41 : 595-604.

EGGHE, L. (1986), The dual of Bradford's law. Journal of the American Society for Information Science, 37 (4) : 246-255.

EGGHE, L. (1990), A note on different Bradford multipliers. Journal of the American Society for Information Science, 41 (3) : 204-209.

EGGHE, L. (2006), Theory and practice of the g-index. Scientometrics, 69 (1) : 131-152.

GLÄNZEL, W. (2003), Bibliometrics as a Research Field: A Course on Theory and Application of Bibliometric Indicators [Course handouts]. Retrieved from: http://www.norslis.net/2004/Bib_Module_KUL.pdf on January 1st, 2008.

GuAN, J., MA, N. (2007), A bibliometric study of China's semiconductor literature compared with other major Asian countries. Scientometrics, 70 (1) : 107-124.

HeDEKER, D., MERMELSTEIN, R. (1996), Application of random-effects regression models in relapse research. Addiction, 91 (Suppl.) : S211-S229.

HedeKer, D., Mermelstein, R. (2000), Analysis of longitudinal substance use outcomes using ordinal random-effects regression models. Addiction, 95 (Suppl. 3) : S381-S394.

Hirsch, J. E. (2005), An index to quantify an individual's scientific research output. Proceedings of the National Academy of Science of the United States of America, 102 (46) : 16569-16572.

LEIMKUHLER, F. F. (1967), The Bradford distribution. Journal of documentation, 23 (3) : 197-207.

LOTKA, A. J. (1926), The frequency distribution of scientific productivity. Journal of the Washington Academy of Science, 16 (12) : 317-323.

LOUGHNER, W. (1992), Lotka's law and the Kolmogorov-Smirnov test: an error in calculation. Journal of the American Society for Information Science, 43 (2) : 149-150.

LyOns, K. S., SAYer, A. G. (2005), Using multilevel modeling in caregiving research. Aging \& Mental Health, 9 (3) : 189-195.

Miettunen, J., Nieminen, P., Isohanni, M. (2002), Statistical methodology in general psychiatric journals. Nordic Journal of Psychiatry, 56 (3) : 223-228.

Miettunen, J., Nieminen, P. (2003), The effect of statistical methods and study reporting characteristics on the number of citations: a study of four general psychiatric journals. Scientometrics, 57 (3) : 377-388.

Nicholls, P. T. (1986), Empirical validation of Lotka's law. Information Processing \& Management, 22 (5) : 417-419.

NichOLLS, P. T. (1989), Bibliometric modeling processes and the empirical validity of Lotka's law. Journal of the American Society for Information Science, 40 (6) : 379-385.

PAO, M. L. (1985), Lotka's law: a testing procedure. Information Processing \& Management, 21 (4) : 305-320.

PotTer, J. (1981), The development of social psychology: consensus, theory and methodology in the British journal of social and clinical psychology. British Journal of Social Psychology, 20 (4) : 249-258.

R DEVElopment CORE TEAM, (2008), $R$ : a language and environment for statistical computing [Computer software]. Vienna, Austria. Retrieved from http://www.r-project.org

SAAD, D. (2006), Exploring the h-index at the author and journal levels using bibliometric data of productive consumer scholars and business-related journals respectively. Scientometrics, 69 (1) : 117-120.

Van Os, J., Driessen, G., Gunther, N., Delespaul, P. (2000), Neighborhood variation in incidence of schizophrenia. British Journal of Psychiatry, $176: 243-248$.

VAN RAAN, A. F. J. (2003), The use of bibliometric analysis in research performance assessment and monitoring of interdisciplinary scientific developments. Technikfolgenabschätzung - Theorie und Praxis, 1 (12) : 20-29.

VAN RAAN, A. F. J. (2006), Comparison of the Hirsch-index with standard bibliometric indicators and with peer judgment for 147 chemistry research groups. Scientometrics, 67 (3) : 491-502. 